\title{
Why is dishonesty difficult to mitigate? The interaction between descriptive norm and monetary incentive
}

i The corrections made in this section will be reviewed and approved by a journal production editor.

Amab Mitra,a․․amitra@pdx.edu, Quazi Shahriar,'1 qshahria@sdsu.edu


States

bepartment of Economics, San Diego State University, 5500 Campanile Dr, San Diego, CA 92182, United States

The authors are grateful to the associate editor of the joumal and two anonymous reviewers for their prescient comments on earlier versions of the manuscript. The authors also acknowledge helpful comments on preliminary data from Subhasish Dugar,Gautam Gupta, Abhishek Das, and Southem Economic Association_(2014) and Edwards Bayesian Research_(2015)_ conference participants. Part of the research was funded by the Faculty_Enhancement Award 2016-17, Portland State University

\begin{abstract}
We examine whether changes in perceived norm of dishonesty can offset the effects of changes in benefit from the dishonest action. We find partial support for the hypothesis in laboratory experiments on lying behavior in a cheap-talk sender-receiver game, conducted in two countries. In the experiments, we vary benefit from lying and shift senders' norm perception by providing them information on lying from prior sessions. The findings suggest that senders adjust their perceived norm as expected, but they respond to norm in a somewhat self-serving manner. Specifically, when benefit from lying is lowered but senders are induced to believe in a higher norm of lying, they lie significantly more than when norm is not intervened. However, when benefit from lying is raised, our intervention to shift perceived norm of lying downward succeeds in altering senders' belief as intended, but does not lower lying significantly. The results can be conceived as an indirect evidence of the challenge in curbing dishonesty by reducing private pecuniary gains in a society with a culture
\end{abstract}


of dishonesty, while suggesting that even societies with history of low dishonesty may succumb to dishonesty when pecuniary incentives for dishonesty rise.

Keywords: Lying; Deception game; Norm; Incentives; Communication;

Experiment

JEL Classification: C72; C91; C92; D73; D83

\section{Introduction}

Honesty is a moral virtue that is consistently endorsed as desirable across societies, yet we choose not to be honest from time to time (Smith, Smith, \& Christopher, 2007; Hugh-Jones, 20152016). The dilemma arises because dishonesty often serves our self-interest at the expense of our morality and may even cause material loss to others. Moreover, our decisions that involve moral judgement are greatly influenced by social norms (Bartels, Bauman, Cushman, Pizarro, \& McGraw, 2015; Graham, Meindl, Beall, Johnson, \& Zhang, 2016). Due to our proclivity to conform to social norms, our moral judgement regarding dishonesty is shaped by, among other factors, our belief about dishonesty among people around us. ${ }^{2}$

In this paper we focus on the influence of a perceived norm on a particular type of dishonest behavior, and study whether changes in the perceived norm thwart changes in pecuniary benefit from such dishonest behavior. We consider "black lies" - those that benefit the liar at the expense of someone else - and we focus on understanding whether an intervention that nudges the decision-maker to believe in a norm of higher (lower) lying propensity among peers can counteract the effect of a decrease (an increase) in benefit from lying. ${ }^{3}$ Our goal is therefore to examine substitutability, if any, between a non-pecuniary and a pecuniary motivation in the decision-maker's preferences for lying.

We posit that a decision-maker's propensity to lie depends on, among many attributes, the monetary incentives for lying and her perception of the descriptive norm of lying (i.e. her belief about how likely others are to lie in that situation). As such, it might be possible to offset the effect of a change in benefit from lying on the decision to lie by changing the decision-maker's perception of the norm, while holding any other factor that might impact the decision to lie constant. Specifically, we study how lying behavior is influenced by two simultaneous and potentially counteracting changes: the benefit from lying is lowered (raised), and the decision-maker is intervened to believe in a higher (lower) propensity to lie among peers.

To accomplish our goal, we designed laboratory experiments using the "deception game" (Gneezy, 2005), in which an informed "sender" can potentially raise her payoff by lying to an uninformed "receiver". The magnitude by which a sender's lie can raise her payoff represents her pecuniary benefit from lying. In the control sessions of our experiment, the size of the benefit from lying varies: it is either low or high. The treatment sessions of our experiment have the same payoffs as in the control. However, in the treatment sessions, the senders are provided with additional norm-related information (on lying) from control sessions. Depending on whether the additional norm-related information originates from high or low benefit control sessions, the treatment sessions are of two types. The additional norm-related information is provided with the goal of shifting the senders' perception of the descriptive norm of lying up or down, which is reflected in sender belief about lying among peers. We elicit sender belief to ascertain whether the information shifts sender belief in the desired direction.

We conducted the experiments in two countries (US and India), using a between-subjects design. Results from the control sessions indicate that when benefit from lying is low (as opposed to high), the senders believe a lower 
proportion of peers would lie. In addition, the senders in these low benefit control sessions lie significantly less, compared to their counterparts in high benefit control sessions.

In the first type of treatment sessions, we hold the benefit at a low level, and simultaneously provide the senders with norm related information from the high benefit control sessions. The goal of such information provision is to shift the treatment senders' belief about peer lying upward. We observe that these treatment senders indeed change their belief as expected. In addition, they lie significantly more, compared to the senders in the low benefit control sessions. As such, the intervention to shift perceived norm of lying upward is able to thwart the effect of a lowering of benefit from lying.

The second type of treatment sessions are analogous to the first type. In the second type, we hold the benefit at a high level, and simultaneously provide the senders with norm related information from the low benefit control sessions. The goal of such information provision is to shift the senders' belief about peer lying downward. We observe that these senders lower their belief but they do not significantly lower the level of lying, compared to the senders in the high benefit control sessions. Thus, the intervention that shifts perceived norm downward does not quite succeed in mitigating the effect of an increased benefit from lying. Overall, we observe that subjects incorporate a descriptive norm in their preferences for lying in a self-serving manner: they act on their belief about peer lying behavior more when it is beneficial to do so.

The information provided to the senders in the treatment sessions discussed above is "complete" in the sense that it includes two pieces: (i) payoff structure in a prior control session, and (ii) proportion of lying in the same control session. We conduct additional treatment sessions to examine the effect of a "partial" version of the information. The partial version includes information on lying from prior control sessions but excludes any information on the control sessions' payoffs. The purpose of these partial sessions is to develop further insight into senders' preferences, with a view to tracing out the exact piece of information from prior sessions that influences a current sender's decision to lie. The results indicate that the effects of partial information provision are not significantly different from that of complete information provision. We also conduct an additional treatment to assess whether our intervention design generates any experimenter demand effects. We find no evidence for such effects.

Our results contribute to the extant literature, and also point to some policy implications. They indicate that a law and order policy aimed at curbing dishonest behavior (such as lying) via reducing pecuniary incentives for dishonesty may not be sufficient when a society or an organization operates under the norm of a high level of dishonesty. We believe our results may provide an indirect micro-level behavioral explanation for why the level of corruption (another form of dishonest behavior) in countries plagued by corruption problems has not shown sensitivity to improvement in the law and order situation in those countries. ${ }^{4},{ }^{5}$ Our results highlight the importance of the long established social norms of corruption in these countries, among other factors, for the persistence of corruption, even when the potential gains from corruption may have gone down due to improvements in law and order situations.

On the other hand, our results also suggest that in a society in which honesty is the perceived norm and the level of dishonesty is low, the policymakers may not ease up on the measures to curb dishonest behavior, with the hope that the culture of honesty will be self-sustaining. These ideas also point to the significance of tipping the society in one direction or the other, for a fresh start in terms of economic, political or sociological regimes.

\section{Literature review}


Our work relates to two intertwined and broad strands of literature: lying and effects of norm on lying; and effects of norm on tax compliance and other strategic/non-strategic decisions. In what follows, we mention some notable works from each strand. ${ }^{6}$

The seminal work of Gneezy (2005) reports that people exhibit an aversion to lie, and that lying comes at a moral cost. Other studies show that lying aversion varies across individuals (Hurkens \& Kartik, 2009; Gibson, Tanner, \& Wagner, 2013) and that the decision to lie is sensitive to a variety of factors, such as, monetary consequences (Freeman \& Gelber, 2010; Bucciol, Landini, \& Piovesan, 2013; Gibson et al., 2013), payoff uncertainty for the party lied to (Dugar, Mitra, \& Shahriar, 2019), relative strength of incentives and intrinsic cost (Kajackaite \& Gneezy, 2017), strategic considerations (Sutter, 2009), guilt aversion (Charness \& Dufwenberg, 2010; Battigalli, Charness, \& Dufwenberg, 2013), gender (Dreber \& Johannesson, 2008), the extent of lie ( Lundquist, Ellingsen, Gribbe, \& Johannesson, 2009; Fischbacher \& Föllmi-Heusi, 2013), cooperation in prior play (Ellingsen, Johannesson, Lilja, \& Zetterqvist, 2009), prior unfair treatment (Houser, Vetter, \& Winter, 2012), and the nature of group (fixed versus endogenous) that induces different reporting practices (Reuben \& Stephenson, 2013). ${ }^{7}$

Several prominent studies focus on norms and unethicality, in the form of lying, dishonesty, and corruption. Specifically, these studies focus on how various norms shape (un)ethicality in strategic environments. Gino, Ayal, and Ariely (2009) discuss how individual unethicality depends on the saliency of dishonesty, as well as on others' dishonesty as a social norm. Pruckner and Sausgruber (2013) report a field experiment which evinces that a moral reminder increases the level of honesty, whereas, a reminder of the legal norm has no effect. The authors argue that the results are consistent with preferences for honesty, shaped by an internalized social norm. Innes and Mitra (2013) report results from a laboratory experiment in which the monetary consequences of lying are held fixed, but cues on how often others lie (is simulated to) vary. Their results indicate that dishonesty is significantly contagious, but honesty is mostly not. Rauhut (2013) shows bi-directional effects of information about others' lying: such information can restore norm adherence and also can exacerbate normative decay. Fosgaard, Hansen, and Piovesan (2013) disentangle whether contagion in cheating originates from norm conformity or from awareness that cheating is an option to consider, and show that men cheat more under conformity, whereas, women cheat with a greater probability when awareness of cheating as an option increases.

Galeotti, Kline, and Orsini (2017) show violations of a distributive justice norm promote more dishonesty, regardless of whether dishonesty has consequences for income redistribution. Diekmann, Przepiorka, and Rauhut (2015) employ a die throwing experiment and show that though lying increases with the knowledge of other liars (contagion), beliefs about the prevalence of norm violations mitigate the effect of such knowledge. Soraperra et al. (2017) focus on how collaboration in task and norm exposure impact dishonesty, and they show that collaboration induces more dishonesty than exposure. Dimant (2019) shows that anti-social behavior (decision to increase own payoff by reducing a charity's payoff) is more contagious than pro-social behavior, and that social proximity shapes the contagion of anti-social behavior with greater intensity than the contagion of prosocial behavior.

Our paper contributes to the above literature in several ways. We demonstrate how an unethical act (namely, lying) is governed by the interplay between norm and benefit. We also demonstrate that a decision maker's exposure to norms, even when such norms originate from different payoff structures, guides him/her in a selfserving manner. Moreover, we carefully trace out the otherwise latent role of belief, i.e., how a change in benefit from lying changes an individual's perceived norm (belief regarding peer lying) even when norm is not directly intervened; and how a change in norms changes an individual's belief in the same direction, undercutting the 
impact of a change in benefit in the opposite direction. As such, we document that sensitivity of lying to monetary consequences that the literature has established can partly be explained by uncontrolled changes in perceived norms.

We begin our discussion on the second strand of literature by highlighting some norm-related factors that shape the decisions to engage in corruption. Researchers focus on social appropriateness of norm violation vis-a-vis corruption (Banerjee, 2016), effect of descriptive social norms among public officials on bribe offers by firms ( Abbink, Freidin, Gangadharan, \& Moro, 2018), impact of social observability of corruption (Salmon \& Serra, 2017), relative effectiveness of monetary and nonmonetary costs of corruption (Banerjee \& Mitra, 2018), and impact of moral cost (induced by framing) on corruptive behavior (Banerjee, 2015).

Several authors document the important roles norms play in shaping individual behavior with regard to tax compliance. Wenzel (2004) shows, using data from a survey, that Australian taxpayers internalize the social norms and act accordingly, provided they identify themselves with the norm attributing reference group. In two subsequent papers, Wenzel $(2005 \mathrm{a}, 2005 \mathrm{~b})$ argues that for individuals who identify with a group, perceived social norms and tax compliance behavior endogenously impact each other. On the other hand, individuals' selfother discrepancy that originates from a misperception that others' acceptance of tax evasion being greater than one's own undermines own tax compliance. He conducts a field experiment with Australian taxpayers and demonstrates that a feedback mechanism on the misperception helps reduce tax deduction claims.

Bobek, Roberts, and Sweeney (2007) show that the most influential social norm construct that explains tax compliance is taxpayers' own moral beliefs, and the beliefs of those close to them. The second important social norm construct is societal views of proper behavior. Fortin, Lacroix, and Villeval (2007) develop and experimentally test a model of tax evasion that incorporates endogenous interactions (i.e., social conformity effects), exogenous interactions (i.e., fairness effects), and correlated effects. The results trace out the role of fairness effects but reject social conformity. Traxler (2010) highlights that belief management can emerge as an effective policy tool in a heterogeneous society, where norm compliance (regarding tax payment) depends on morale reference groups.

Bobek, Hageman, and Kelliher (2013) show that individuals' tax compliance decisions are directly influenced by personal norms and subjective norms, whereas, such decisions are indirectly influenced by injunctive norms and descriptive norms. Lefebvre, Pestieau, Riedl, and Villeval (2015) report results from an experiment on tax compliance behavior. In two of their treatments, subjects receive information from past experimental sessions on highest (lowest) tax evasion rates. The results indicate that such information has an asymmetric effect: high (low) compliance does not (does) substantially lower (raise) tax evasion for certain probabilities.

Social norm, social influence, and peer effects have been extensively studied in various other contexts, such as the dictator game and the public goods game. Studies in dictator game, for instance, demonstrate that fairness in allocation as a norm is contagious (Bichchieri and Xiao, 2009; Krupka \& Weber, 2009; Cason \& Mui, 1998; Duffy \& Kornienko, 2010). Studies in experimental public goods games indicate that establishment of a norm for contributions (by virtue of enforcements, social approval, punishment etc.) improves the level of individual contributions to the public good (Reuben \& Riedl, 2013; Rege, 2004; Fehr \& Gächter, 2000).

Our paper differs from the works on corruption and tax compliance discussed above. In our setting, a sender may incur a moral cost while engaging in an unethical act (lying), but aside from that, his/her action does not face any potential enforcements, sanctions, or rejections from any other party, which represent the typical settings the papers on corruption and tax compliance employ. Our context also differs from those in dictator games and 
public goods games in that it involves the possibility of deliberate misrepresentation of a fact concerning payoffs. In a dictator game or public goods game, a decision maker may exhibit preferences for selfishness, which is different from preferences for lying that we try to capture (see Innes \& Mitra, 2013).

Overall, the novelty of our study resides in its focus on the interaction of simultaneous changes in the pecuniary incentives of an unethical act and a descriptive norm regarding the act. As indicated earlier, our study also traces out a possible micro level behavioral trait that can partly explain the emergence of a stricter regime of law and order juxtaposed with worsened corruption problem in many countries.

\section{Experimental design \& hypotheses}

\subsection{The games}

Table 1 shows a generic deception game. The game is played between two players: a sender and a receiver. The sender recommends to the receiver one of two possible payoff distributions (described as "options"), A and B. The receiver then, without knowing the actual payoffs under each option, chooses between the two options. Only the sender is informed about the payoff distribution under each option, and this information remains private to her even after the game ends. ${ }^{8}$ In addition, the sender is told that the receiver does not have any information on the payoffs. Assume that $\times>m$ and $n>y$ in Table 1 .

Table 1

The table layout displayed in this section is not how it will appear in the final version. The representation below is solely purposed for providing corrections to the table. To preview the actual presentation of the table, please view the Proof.

A Generic Deception Game.

\begin{tabular}{|l|l|l|}
\hline Option & Sender's Payoff & Receiver's Payoff \\
\hline A & $\$ x$ & $\$ y$ \\
\hline B & $\$ m$ & $\$ n$ \\
\hline
\end{tabular}

The game begins with the sender sending one of the two messages to the receiver, recommending the option that results in a higher payoff to the receiver:

Message-A: "Option a will earn you (my receiver) more money than Option B"

Message-B: "Option b will earn you (my receiver) more money than Option A".

The message is basically a "cheap-talk", as it is costless and non-binding. Since $n>y$, Message-A is a lie. ${ }^{9}$ After receiving the message, the receiver ends the game by choosing one of the two options, which determines the final payoffs to both players. The receiver only learns about the amount he has earned from the implemented option, but not what he could have earned had he chosen the other option. As such, he can never determine whether the received message is truthful or not. 
Next, we assign two sets of values to the parameters ( $x, y, m$ and $n)$ in order to vary the sender's potential (net) benefit from lying, given by $(x-m) .{ }^{10}$ We conducted our experiments in the United States and in India. (The rationale for running experiments at a second location is discussed later.) Tables 2 shows the experimental games, parameterized in local currencies (Dollar and Rupee).

\section{Table 2}

The table layout displayed in this section is not how it will appear in the final version. The representation below is solely purposed for providing corrections to the table. To preview the actual presentation of the table, please view the Proof.

Deception Games and Treatments.

\begin{tabular}{|c|c|c|c|c|c|c|c|}
\hline & & US & & India & & Control & Inter \\
\hline Games & Option & Sender'sPayoff & Receiver'sPayoff & Sender'sPayoff & Receiver'sPayoff & Treatments & Trea1 \\
\hline \multirow{2}{*}{$\begin{array}{l}\text { High } \\
\text { Benefit(HB) }\end{array}$} & $\mathrm{A}$ & $\$ 19$ & $\$ 5$ & Rs 450 & Rs 200 & \multirow{2}{*}{ HB Control } & \multirow{2}{*}{$\mathrm{HB}-l \mathrm{c}$} \\
\hline & $\mathrm{B}$ & $\$ 5$ & $\$ 19$ & Rs 200 & Rs 450 & & \\
\hline \multirow{2}{*}{$\begin{array}{l}\text { Low } \\
\text { Benefit(LB) }\end{array}$} & A & $\$ 12$ & $\$ 5$ & Rs 325 & Rs 200 & \multirow{2}{*}{ LB Control } & \multirow{2}{*}{ LB- $h$} \\
\hline & $\mathrm{B}$ & $\$ 5$ & $\$ 19$ & Rs 200 & Rs 450 & & \\
\hline
\end{tabular}

In Table 2, the first game is labeled as High Benefit (HB) in which the sender earns \$19 (Rs 450) under OptionA, and only \$5 (Rs 200) under Option-B. As such, the sender can potentially gain \$14 (Rs 250) by lying. Such lying, on the other hand, can potentially reduce the receiver's payoff by $\$ 14$ (Rs 250), from \$19 (Rs 450) under Option-B to $\$ 5$ (Rs 200) under Option-A. In the second game in Table 2, labeled as Low Benefit (LB), the sender's potential (net) benefit from lying is reduced to $\$ 7$ (Rs 125), however, the potential loss to the receiver is the same as in HB. ${ }^{11}$

\subsection{Experimental treatments \& hypotheses}

Our main experimental goal is to study two questions that are mirror images of each other. First, suppose the senders' perceived norm of lying is intervened to be higher (than when norm is not intervened). If so, can such an intervention thwart the desirable effect of a reduction in the benefit from lying? Second, suppose the senders' perceived norm of lying is intervened to be lower (than when norm is not intervened). If so, can such an intervention of norm mitigate the undesirable impact of an increase in the benefit from lying? To answer these questions, we design four treatments, the two controls (without intervention of perceived norm) and the two intervention treatments, as listed in Table 2.

We follow a simple two-step approach using a between-subjects design. First, we let two sets of subjects play the HB and the LB games. These two games form our controls. We not only expect to see a higher proportion of lie (i.e., ratio of the number of Message-A to the total number of the messages) in HB than in LB, but also expect senders' belief about the norm of lying among peers to be higher in HB than in LB. Only after confirming this from elicited sender belief, we plan to proceed to the second step. 
In the second step, we conduct the intervention treatments, labeled as LB-high_norm and HB-low_norm. In the LB-high_norm (HB-low_norm) treatment, subjects play the LB (HB) game in which senders, before they make their decision, are provided with two additional pieces of information from the HB Control (LB Control) treatment: (i) the payoffs under the two options in the HB Control (LB Control) treatment, and (ii) the number and corresponding percentage of senders who lied and those who told the truth in the HB Control (LB Control) treatment. Note that the additional information is flipped: subjects participating in LB-high_norm are provided information from HB Control; likewise, HB-low_norm participants are provided information from LB Control. 12 By providing these additional information, we expect to have changed senders' perceived norm of lying. Specifically, we expect that when senders in LB-high_norm (HB-low_norm) are informed of the proportion of lie in HB Control (LB Control), their belief about the proportion of lying peers would be higher (lower) than that in the absence of such intervention. Elicitation of sender belief helps us check if we are actually successful in changing the senders' perceived norm in the desired direction. The next section discusses the belief elicitation process in detail.

If the intervention of perceived norm is potent enough to change lying decisions substantially, then we expect the proportion of lie in LB-high_norm (HB-low_norm) to be higher (lower) than the same in LB Control (HB Control). We summarize this conjecture in the following testable hypotheses.

\section{Hypotheses:}

(a) Effect of a change in monetary benefit: In comparison to HB Control, the proportion of lie is lower in LB Control.

(b) Effect of an upward shift of perceived norm: In comparison to LB Control, the proportion of lie is higher in LB-high_norm.

(c) Effect of a downward shift of perceived norm: In comparison to HB Control, the proportion of lie is lower in HB-low_norm.

The extant literature offers support for the directionality of the hypotheses. Part (a) is based on Gneezy (2005) which shows that the propensity to lie increases as the benefit from lying increases. Innes and Mitra (2013), Lefebvre et al. (2015), and Abbink et al. (2018) study different issues, but they all show that a decision maker's perception of unethicality among others and his/her propensity to engage in an unethical act have a direct relationship. These studies provide support for the directionality in parts (b) and (c) which are formed on basis that, holding the benefit from lying constant, a sender's propensity to lie changes with her perceived norm of lying among peers. ${ }^{13}$

We close our discussion of the hypotheses by showing that they imply that a shift in perceived norm can counteract the effect of a change in benefit. Let $p_{H B}$ and $p_{L B}$ denote the proportion of lie in the two control treatments which differ in the monetary benefit from lying. The difference between $p_{H B}$ and $p_{L B}$ thus captures the effect of a reduction in the benefit from lying on the propensity to lie, and Part (a) of the hypotheses posits that $p_{H B}>p_{L B}$. Now, suppose $p_{H B_{-} L N}$ and $p_{L B_{-} H N}$ are the proportions of lying in the two intervention treatments, HB-low_norm and LB-high_norm, respectively. Then part (b) of the hypotheses asserts that $p_{L B_{-} H N}>p_{L B}$. If we multiply both sides by -1 and add $p_{H B}$ to both sides of the above inequality, we obtain $\left(p_{H B}-p_{L B_{-} H N}\right)<\left(p_{H B}-p_{L B}\right)$. The right side of this inequality captures the effect of the reduction in benefit from lying, as stated earlier. The left side, along with the effect of the same reduction in benefit, reflects the effect of the intended upward shift of perceived norm in LB-high_norm. Since the left side is smaller than the right side, 
part (b) of the hypotheses implies that an intervention to shift perceived norm of lying among peers upward can counteract the reduction in benefit from lying. Similarly, we can show part that (c) of the hypotheses implies $\left(p_{H B \_L N}-p_{L B}\right)<\left(p_{H B}-p_{L B}\right)$. That is, an intervention to shift perceived norm of lying among peers downward can mitigate the impact of an increment in benefit from lying.

\subsection{Experimental procedures}

All experimental sessions were conducted at the San Diego State University, US; and the Jadavpur University, India, and undergraduate students were recruited to participate. ${ }^{14}$ It is not our goal to compare between the experimental results obtained from these two countries; instead, we are interested in assessing whether the hypotheses hold true for different subject populations.

In each session, we recruited an even number of subjects who participated in one (and only one) of the treatments for a single shot play of the relevant deception game. Half of them were randomly assigned the role of the sender and the other half the role of the receiver. The two groups were seated in separate rooms and were never at the same place at the same time. To assist the experimenter, two monitors, one for each room, were recruited for each session. Each treatment in our experiment consisted of 3 to 4 sessions. The average group size was 12 pairs of subjects. In total, we recruited 176 and 169 pairs of sender-receiver in the US and India, respectively.

After a group arrived at the designated room, each subject was randomly assigned a registration number in a double-blind protocol; the number remained anonymous to other subjects and also to the experimenter. The registration numbers were used to randomly match a sender to a receiver. Each subject was then given a copy of the instructions and, in addition, the experimenter read aloud the instructions. After all questions from the subjects were answered in private, the experiment moved on to the decision-making stage.

Each sender was given a "message card" which had Message-A and Message-B printed on it; the sender simply had to circle the message she wanted to send. Once the senders made their decisions, the cards were collected, and the experimenter carried those to the receivers' room. Each sender's message card was then privately passed on to her matched receiver. Upon seeing the message, each receiver chose between the two options on a piece of paper, called the "decision card". After the receivers made their decisions, the cards were collected and payments were determined. After that, the receivers were paid privately, in cash. Finally, the experimenter moved back to the senders' room to conduct a small incentivized questionnaire. In the end, the senders were paid according to the option the matched receiver chose, plus the amount they earned from the questionnaire. To maintain anonymity, we placed subjects' earnings in separate envelopes with registration numbers written on them and laid them on a table. Subjects picked up their envelope on the way out.

To nullify any potential sender-belief that receivers may act strategically, senders were told (based on the results from Gneezy, 2005) in the instructions that approximately $80 \%$ receivers in a similar experiment in the past had chosen the option recommended by their respective sender, as in Innes and Mitra (2013). ${ }^{15}$ The questionnaire was designed to elicit sender belief about (i) peer behavior and (ii) receiver behavior. Each sender was asked to predict the proportion of senders she believed lied in her session. The senders made their choice from a set of five-percentage-point bandwidths: 0-5\%, 6-10\%, ..., 96-100\%. We paid each sender $\$ 1$ (Rs 20) for marking a choice that was either correct (i.e., matched with the actual percentage) or was within the two adjacent fivepercentage-point bandwidths, plus or minus, from the actual percentage. 
The question on peer behavior was included in the questionnaire to help us measure senders' perception about the norm of lying in the treatment they participated in. It thus enables us to check whether: (a) such perception is higher in HB Control than in LB Control, and (b) the intervention treatments are effective in swaying sender perception in the intended direction, as discussed earlier. Each sender also indicated in the questionnaire her belief on whether the matched receiver would accept the recommendation. Each sender was rewarded additional \$1 (Rs 20) for correct prediction. The question on receiver behavior was aimed at verifying whether the senders believed the receivers would not act strategically, and therefore would follow the recommendation.

Senders and receivers never learned each other's actual identity during or after the experiment. The receivers were never told whether the matched sender was truthful. The monitors were specifically assigned the task of promoting anonymity and preventing any form of communication among the subjects.

We now focus on the process of information transmission from the control treatments to the intervention treatments. To pass on the information about the rate of lying from HB Control (LB Control) to the senders in LB-high_norm (HB-low_norm) in a subtle manner and to minimize the possibility that the information is suggestive of expected behavior, the experimental instructions in LB-high_norm (HB-low_norm) presented the information as an illustrative example of the experimental procedure and the nature of the data the experiment generated. As indicated before, the instructions in LB-high_norm (HB-low_norm) clearly and truthfully indicated that: (i) the data came from actual sessions, (ii) the decision-making situations in those sessions were similar but the payoffs were different, and (iii) the actual payoffs in HB Control (LB Control). As such, senders in LB-high_norm (HB-low_norm) were given complete information on the payoffs and the summary statistics of sender decisions in HB Control (LB Control).

\section{Results}

Our main interest is in whether the sender chooses Message-A (lie) or Message-B (truthful). Table 3 reports the number of senders, the number of those who lied and the resulting proportion of lie for each treatment in the two countries. The numbers for the India experiment are presented in parentheses. Combining all treatments, 70\% (65\%) of the 176 (169) senders from the US (India) lied. Table 3 also reports summary statistics on two additional variables constructed from data collected from the questionnaire - Female, which is an indicator for female senders, and Deaf-receiver, which is an indicator for senders who believed their respective receiver would not follow recommendation.

Table 3

The table layout displayed in this section is not how it will appear in the final version. The representation below is solely purposed for providing corrections to the table. To preview the actual presentation of the table, please view the Proof.

Summary of Sender Composition, Decisions and Belief about Receiver Credulity.

\begin{tabular}{|c|c|c|c|c|c|}
\hline $\begin{array}{l}\text { Experimental } \\
\text { Treatments }\end{array}$ & $\begin{array}{l}\text { Number of } \\
\text { Senders }\end{array}$ & $\begin{array}{l}\text { Proportion of } \\
\text { Female }\end{array}$ & $\begin{array}{l}\text { Number of Lying } \\
\text { Senders }\end{array}$ & $\begin{array}{l}\text { Proportion of Lying } \\
\text { Senders }\end{array}$ & $\begin{array}{l}\text { Proportion of Deaf- } \\
\text { receiver }\end{array}$ \\
\hline HB Control & $\begin{array}{l}45 \\
(45)\end{array}$ & $\begin{array}{l}0.31 \\
(0.49)\end{array}$ & $\begin{array}{l}35 \\
(33)\end{array}$ & $\begin{array}{l}78 \% \\
(73 \%)\end{array}$ & $\begin{array}{l}0.16 \\
(0.29)\end{array}$ \\
\hline LB Control & 47 & 0.45 & 27 & $57 \%$ & 0.17 \\
\hline
\end{tabular}




\begin{tabular}{|l|l|l|l|l|l|}
\hline \multicolumn{1}{|l|}{$(36)$} & $(0.56)$ & $(19)$ & $(53 \%)$ & $(0.17)$ \\
\hline \multirow{2}{*}{ LB-high_norm } & $\begin{array}{l}42 \\
(42)\end{array}$ & $\begin{array}{l}0.50 \\
(0.50)\end{array}$ & $\begin{array}{l}31 \\
(30)\end{array}$ & $\begin{array}{l}74 \% \\
(71 \%)\end{array}$ & $\begin{array}{l}0.17 \\
(0.19)\end{array}$ \\
\hline HB-low_norm & $\begin{array}{l}42 \\
(46)\end{array}$ & $\begin{array}{l}0.33 \\
(0.39)\end{array}$ & $\begin{array}{l}30 \\
(28)\end{array}$ & $\begin{array}{l}71 \% \\
(61 \%)\end{array}$ & $\begin{array}{l}0.24 \\
0.22)\end{array}$ \\
\hline Total & $\begin{array}{l}(76) \\
(169)\end{array}$ & $\begin{array}{l}0.40 \\
(0.48)\end{array}$ & $\begin{array}{l}123 \\
(110)\end{array}$ & $\begin{array}{l}70 \% \\
(65 \%)\end{array}$ & 0.18 \\
\hline
\end{tabular}

Note: The results from the India experiment are reported within parentheses. Female is a dummy variable that represents if the decision-maker is a female. Deaf-receiver is a dummy variable for senders who believe their respective receiver would not follow recommendation.

Below, we first discuss results from proportion tests and regression-based tests of our hypotheses. Then we discuss elicited sender belief, with a view to developing insights into perceived norm of lying in the control treatments and how the intervention treatments may have changed such perceived norm.

\subsection{Hypotheses testing using proportion Tests:}

We begin by examining part (a) of our hypotheses. Specifically, since lying is more beneficial in HB Control than in LB Control, we expect the proportion of lie to be higher in the former than in the latter. ${ }^{16}$ As Table 3 shows, the data supports part (a) of our hypotheses: 78\% (73\%) and 57\% (53\%) of the senders lied in HB Control and LB Control, respectively. Table 4 shows the results of $Z$-tests for difference in proportion of lie between pairs of treatments. The results reveal that the difference between HB Control and LB Control is statistically significant.

(i) The table layout displayed in this section is not how it will appear in the final version. The representation below is solely purposed for providing corrections to the table. To preview the actual presentation of the table, please view the Proof.

Test for Treatment Differences in Proportion of Lying.

\begin{tabular}{|c|c|c|c|}
\hline $\begin{array}{l}\text { Experimental } \\
\text { Treatments }\end{array}$ & $\begin{array}{l}\text { LB Control } \\
57 \%(53 \%)\end{array}$ & $\begin{array}{l}\text { LB-high_norm } \\
74 \%(71 \%)\end{array}$ & $\begin{array}{l}\text { HB-low_norm } \\
71 \%(61 \%)\end{array}$ \\
\hline $\begin{array}{l}\text { HB Control } \\
78 \%(73 \%)\end{array}$ & $\begin{aligned} Z & =2.15, p_{t}=0.032 * * \\
p_{o} & =0.016 * * \\
(Z & =1.86, p_{t}=0.062 * \\
p_{o} & =0.031 * *)\end{aligned}$ & $\begin{array}{l}\mathrm{Z}=0.44, \mathrm{p}_{\mathrm{t}}=0.662 \\
\mathrm{p}_{\mathrm{o}}=0.331 \\
\left(\mathrm{Z}=0.21, \mathrm{p}_{\mathrm{t}}=0.836\right. \\
\left.\mathrm{p}_{\mathrm{o}}=0.418\right)\end{array}$ & $\begin{array}{l}Z=0.75, p_{t}=0.454, p_{o}=0.227 \\
\left(Z=1.22, p_{t}=0.224,\right. \\
\left.p_{o}=0.112\right)\end{array}$ \\
\hline $\begin{array}{l}\text { LB-high_norm } \\
74 \%(71 \%)\end{array}$ & $\begin{aligned} Z & =1.68, p_{t}=0.094 * \\
p_{o} & =0.047 * * \\
(Z & \left.=1.64, p_{t}=0.102, p_{o}=0.051 *\right)\end{aligned}$ & - & $\begin{array}{l}\mathrm{Z}=0.31, \mathrm{p}_{\mathrm{t}}=0.758, \mathrm{p}_{\mathrm{o}}=0.379 \\
\left(\mathrm{Z}=0.99, \mathrm{p}_{\mathrm{t}}=0 ., \mathrm{p}_{\mathrm{o}}=0.162\right)\end{array}$ \\
\hline $\begin{array}{l}\text { LB Control } \\
57 \%(53 \%)\end{array}$ & - & Refer to the above row & $\begin{array}{l}\mathrm{Z}=-1.37, \mathrm{p}_{\mathrm{t}}=0.171 \\
\mathrm{p}_{\mathrm{o}}=0.086^{*} \\
\left(\mathrm{Z}=-0.73, \mathrm{p}_{\mathrm{t}}=0.467\right. \\
\left.\mathrm{p}_{\mathrm{o}}=0.233\right)\end{array}$ \\
\hline
\end{tabular}


Note: Results from the India experiment are reported within parentheses. $Z$-statistics are calculated for the difference in proportions in row and column treatments in the above matrix. The results in italics and bold font correspond to our hypotheses $(\mathrm{a}, \mathrm{b}$ and $\mathrm{c}) . p_{t}$ is the two-tailed $p$-value (alternative hypothesis, $\mathrm{H}_{1}$ : row $\neq$ column) and $p_{o}$ is the one-tailed $p$ value (alternative hypothesis, $\mathrm{H}_{1}$ : row $>$ column). One-tailed test results are appropriate for all three of our hypotheses, since they are directional (see Section 3 ). We report two-tailed $p$-values for them for completeness. $* * *, * *$ and $*$ denote statistical significance at $1 \%, 5 \%$ and $10 \%$ level, respectively.

Next, we check whether senders are responsive to the intervention designed to shift perceived norm of lying upward, while benefit from lying is held constant, as part (b) of our hypotheses predicts. Recall that senders participating in LB-high_norm faced the same payoff consequences as in LB Control; however, they were informed before they chose their message that 78\% (73\%) of prior senders lied. Per our experimental design, this information was taken from HB Control. As in part (b) of the hypotheses, our expectation is that the intervention would lead to a higher proportion of lie in LB-high_norm than in LB Control. We see a substantial impact of the intervention - the proportion of lie in LB-high_norm jumped to 74\% (71\%) from 57\% (53\%) observed in LB Control; the difference is (marginally) significant, as Table 4 shows. As such, we fail to reject part (b).

Part (c) of the hypotheses focuses on whether, holding benefit from lying constant, an intervention to shift perceived norm of lying downward leads to a decrease in the proportion of lie. Recall that HB Control and HBlow_norm have the same payoff consequences, while HB-low_norm implements the desired intervention by informing the senders in HB-low_norm, before they made their decision, that 57\% (53\%) of prior senders lied (as was observed in LB Control). Our expectation is that the proportion of lie would be lower in HB-low_norm than in HB Control. Table 3 shows that the proportion of lie in HB-low_norm was 71\% (61\%), somewhat lower than 78\% (73\%) we observed in HB Control. However, the difference is not statistically significant, as shown in Table 4. As such, we reject part (c) of the hypotheses.

\subsection{Hypotheses testing using regression models}

We estimate Probit regression models to check for the treatment effects. The marginal effects are reported in Table 5. The binary dependent variable is whether or not a sender lies, and the covariates include the treatment dummies, Female and Deaf-receiver. The reported marginal effects indicate by how much the probability of lying increases or decreases in a treatment, in comparison to LB Control, which serves as the base (omitted) treatment. Our expectations are as follows: the marginal effect of HB Control to be positive and statistically significant (part (a) of the hypotheses), the marginal effect of LB-high_norm to be positive and statistically significant (part (b) of the hypotheses), and the marginal effect of HB-low_norm to be significantly lower than that of HB Control (part (c) of the hypotheses).

Table 5

The table layout displayed in this section is not how it will appear in the final version. The representation below is solely purposed for providing corrections to the table. To preview the actual presentation of the table, please view the Proof.

Marginal Effects from Probit Regression on Lying.

\begin{tabular}{|c|c|c|c|}
\hline & US & India & Pooled \\
\hline HB Control & $0.18 * *(0.08)$ & $0.23 *(0.09)$ & $0.20 * * *(0.06)$ \\
\hline
\end{tabular}




\begin{tabular}{|l|l|l|l|}
\hline LB- $h$ igh_norm & $0.15^{*}(0.08)$ & $0.19^{*}(0.09)$ & $0.16^{* *}(0.06)$ \\
\hline HB-low_norm & $0.13(0.08)$ & $0.10(0.10)$ & $0.11^{*}(0.06)$ \\
\hline Female & $-0.06(0.07)$ & $0.03(0.08)$ & $-0.02(0.05)$ \\
\hline Deaf-receiver & $-0.21^{* *}(0.10)$ & $-0.32^{* * *}(0.09)$ & $-0.26^{* * *}(0.07)$ \\
\hline India & - & - & $-0.05(0.05)$ \\
\hline Obs. & 176 & 169 & 345 \\
\hline$R^{2}$ & 0.05 & 0.07 & 0.06 \\
\hline Log likelihood & -102.28 & -101.20 & -204.37 \\
\hline
\end{tabular}

Note: The dependent variable is sender message choice (lie $=1$, truthful $=0$ ). LB Control is the omitted/reference treatment. Female is a dummy variable that represents female decision-makers. Deaf-receiver is a dummy variable for senders who believe their respective receiver would not follow recommendation. India is a dummy variable that represents observations from the India experiment. Standard errors are in parentheses. $* * *, * *$ and $*$ denote statistical significance at $1 \%, 5 \%$ and $10 \%$ level, respectively.

As Table 5 shows, the marginal effects for HB Control and LB-high_norm are indeed positive and statistically significant, but marginally so in the case of LB-high_norm. Using a Wald test, we fail to reject the null hypothesis that the marginal effects of HB-low_norm and HB Control are the same against the alternative hypothesis that the former is lower than the latter $(p=0.300(p=0.129)$ for the US (India) experiment and $p=0.144$ for the pooled data). As such, we again fail to find support for part (c) of the hypotheses. Overall, the results from the regression models are very much similar to those from the proportion tests we reported earlier.

\subsection{Perceived norm and the effect of intervention}

Recall that we presumed senders' perceived norm about peer lying to be different between the two control treatments, and that the intervention treatments would change the perceived norm to lead to the treatment effects. To test these premises, we utilize data on the elicited sender belief. In the analysis that follows, we sequentially answer three questions: (i) Was belief about peer lying lower in LB Control than in HB Control to begin with, and was the difference large enough so that there was actually a scope for our intervention treatments to change belief in the intended direction? (ii) Was the intervention effective in changing sender belief in LB-high_norm and HB-low_norm the way we intended? That is, was belief regarding peer lying significantly higher in LBhigh_norm than in LB Control, and lower in HB-low_norm than in HB Control? (iii) Were sender decisions consistent with their belief? That is, did an increase in belief regarding peer lying increase lying?

Fig. 1 speaks to question (i). It describes average sender belief about the proportion of lying peers and the corresponding actual proportion of lie, which we have already discussed. We observe that senders in LB Control believed $66 \%$ (46\%) of the peers lied, while the same for HB Control was $74 \%(55 \%)$; the difference between LB Control and HB Control is statistically significant for both countries. ${ }^{17}$ As such, it was indeed feasible to carry out the intended interventions, i.e., to orient sender belief in LB-high_norm to a higher level, and that in HB-low_norm to a lower level. 

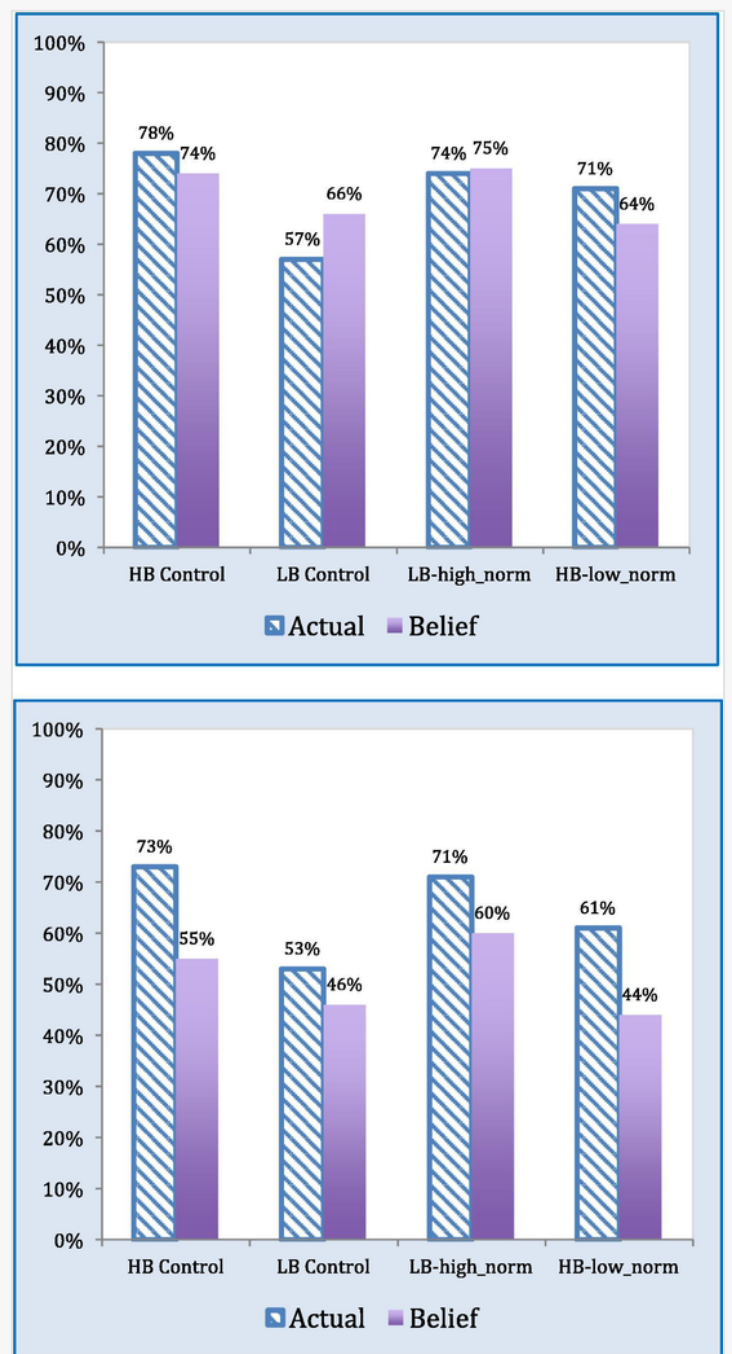

Actual Proportion and Elicited Belief About Proportion of Lie, (US on the Upper Panel; India on the Lower Panel).

We now focus on the belief data for the two intervention treatments to answer question (ii). We find that interventions were indeed effective. Our expectation was that senders in LB-high_norm (HB-low_norm) would believe in a higher (lower) proportion of lie among peers than those in LB Control (HB Control). Fig. 1 is consistent with this expectation. The senders in LB-high_norm believed 75\% (60\%) of the fellow senders would lie, whereas the same proportion in LB Control was $66 \%$ (46\%). The difference is statistically significant; even though the significance level is marginal for the US data. ${ }^{18}$ On the other hand, the senders in HB-low_norm believed 64\% (44\%) of the peer senders would lie, whereas the same proportion in HB Control was $74 \%(55 \%)$. Once again, the difference is statistically significant. ${ }^{19}$

In order to answer questions (i) and (ii) using regressions, we ran Tobit regression models of individual sender belief on treatment dummies. ${ }^{20}$ Table 6 reports the results. As before, LB Control serves as the base (omitted) treatment, and we expect to observe the marginal effects for HB Control and LB-high_norm to be statistically significant and positive, and the marginal effect for HB-low_norm to be lower than the same for HB Control. We find that compared to LB Control, belief is significantly higher (approximately 9\%) in HB Control in both countries (supporting (i)). We also observe that belief in LB-high_norm is significantly higher by a margin of $10 \%(13 \%)$ than in LB Control (supporting (ii)). In addition, belief is lower in HB-low_norm than in HB Control (supporting (ii)). ${ }^{21}$ 
The table layout displayed in this section is not how it will appear in the final version. The representation below is solely purposed for providing corrections to the table. To preview the actual presentation of the table, please view the Proof.

Marginal Effects from Tobit Regression on Sender Belief about Peer Lying.

\begin{tabular}{|l|l|l|}
\hline & US & India \\
\hline HB Control & $8.54 *(4.69)$ & $8.81 *(4.63)$ \\
\hline LB-high_norm & $9.82 * *(4.72)$ & $13.04 * *(4.70)$ \\
\hline HB-low_norm & $-1.91(4.73)$ & $-3.59(4.63)$ \\
\hline Female & $0.60(3.69)$ & $-4.91(3.20)$ \\
\hline Intercept & $65.14 * * *(5.97)$ & $44.12 * * *(3.73)$ \\
\hline Obs. & 176 & 169 \\
\hline$R^{2}$ & 0.01 & 0.01 \\
\hline Log Likelihood & -795.52 & -751.58 \\
\hline
\end{tabular}

Note: Dependent variable: elicited sender belief about the proportion of lying peers. LB Control is the omitted/reference treatment. Female is a dummy variable that represents if the decision-maker is a female. Standard errors are in parentheses. $* * *, * *$ and $*$ denote statistical significance at $1 \%, 5 \%$ and $10 \%$ level, respectively.

Next, we turn to question (iii). If we consider the belief data and the decision data together, as in Fig. 1, we see that variations in decisions across treatments are consistent with the way sender belief varied across these treatments. It shows that an increase in sender belief about peer lying is associated with an increase in lying. This association helps us assert that the effects of interventions on the decisions to lie is due to the effectiveness of the interventions in changing sender belief.

Finally, we present in Table 7 results from a few additional Probit regressions to examine the effect of sender belief about peer lying on sender's decision to lie. The binary dependent variable is whether or not a sender lies. Regression model (1) only includes treatment variables - whether the benefit from lying is low or high, and whether the norm perception is intervened. The results for model (1) basically reproduce the findings on treatment effects discussed earlier (Table 5). Our main interest is in model (2) of Table 7 which includes controls for sender belief. We see that the inclusion of sender belief turns the marginal effect of the indicator variable for intervention statistically insignificant. This observation enables us to assert with greater confidence that the effects of perception intervention work via sender perception of the norm of peer lying. We also notice how powerful sender belief about peer lying is in shaping decision: in Table 7, a $1 \%$ increase in belief leads to a $1 \%$ increase in lying.

(i) The table layout displayed in this section is not how it will appear in the final version. The representation below is solely purposed for providing corrections to the table. To preview the actual presentation of the table, please view the Proof. 


\section{(1)}

(2)

(1)

(2)

\begin{tabular}{|l|l|l|l|l|}
\hline Sender Belief & - & $0.01 * *(0.002)$ & - & $0.01 * *(0.002)$ \\
\hline High Benefit $(H B)$ & $0.19^{* *}(0.09)$ & $0.14(0.10)$ & $0.26^{* *}(0.11)$ & $0.21^{*}(0.11)$ \\
\hline Intervention & $0.16^{*}(0.09)$ & $0.07(0.10)$ & $0.20^{*}(0.11)$ & $0.07(0.11)$ \\
\hline$H B \times$ Intervention & $-0.23(0.15)$ & $-0.04(0.16)$ & $-0.37 * *(0.15)$ & $-0.15(0.17)$ \\
\hline Female & $-0.06(0.07)$ & $-0.08(0.08)$ & $0.03(0.08)$ & $0.08(0.08)$ \\
\hline Deaf-receiver & $-0.21 * *(0.10)$ & $-0.11(0.10)$ & $-0.32 * * *(0.09)$ & $-0.42 * * *(0.10)$ \\
\hline Obs. & 176 & 176 & 169 & 169 \\
\hline$R^{2}$ & 0.05 & 0.23 & 0.07 & 0.23 \\
\hline Log likelihood & -102.28 & -82.94 & -101.20 & -84.02 \\
\hline
\end{tabular}

Note: Dependent variable: sender message choice $(l i e=1$, truth $=0)$. LB Control is the omitted/reference treatment. Sender Belief is a sender's belief about the proportion of lying peers. High Benefit is a dummy for high benefit of lying. Intervention is a dummy for the intervention treatments. Female is a dummy variable that represents if the decision-maker is a female. Deaf-receiver is a dummy variable for senders who believed their respective receiver would not follow recommendation. The difference between (1) and (2) is that the latter one includes Sender Belief. Standard errors are in parentheses. ***, ** and * denote statistical significance at $1 \%, 5 \%$ and $10 \%$ level, respectively.

Tables 6 and 7 together provide a complete picture of the two-step process: how provision of norm-related information affects lying decision, via changes in perceived norm. Table 6 establishes the first step in which information provision changes senders' perceived norm of lying (measured by sender belief regarding peer lying), and Table 7 demonstrates the second step in which changes in perceived norm change senders' propensity to lie.

\section{Discussion}

In this section we address several issues related to our design and interpretation of our results. First, we would like to test robustness of the results with a design based on "partial" information feedback. Recall that, in the complete information version of the treatment LB-high_norm (HB-low_norm), senders were provided with information on the proportion of lie and the payoffs in HB Control (LB Control). However, information available to a decision maker in real life is often partial. An individual may develop a fairly good idea about the overall level of (dis)honesty in the society by reading newspapers/reports, watching television etc. However, he/she might not have complete knowledge about the magnitude of material benefit one can accrue by being dishonest, because dishonest actions are clandestine and their magnitude varies, and estimates of gains and losses due to dishonesty are questionable.

To address the issue discussed above, we conducted two more treatments: LB-partial and HB-partial. In LBpartial (HB-partial), we informed the senders about the proportion of lie and truth observed in HB Control (LB Control), but we did not share any information about the payoffs in HB Control (LB Control). To reiterate, for instance, senders participating in LB-partial (HB-partial) in the US experiment were informed that in a past similar session $22 \%$ senders told the truth and $78 \%$ lied (43\% senders told the truth and $57 \%$ lied). In specific terms, we (the experimenters) categorically announced during the sessions that no additional information on 
payoffs would be provided. Clearly, the design not only speaks to the issue of partial information in real life, but it also ascertains that nothing else other than a norm related information is provided.

Table 8 reports the data from LB-partial and HB-partial treatments, along with the results of $Z$-tests for difference in proportions. Recall that the proportion of lie in LB-high_norm was 74\% (71\%) in the US (India) experiment. Though this proportion is slightly lower than the $78 \%(76 \%)$ level in LB-partial, the difference is not statistically significant. The same proportion in HB-low_norm was $71 \%$ (61\%), which is also not statistically significantly different from the observed level of $68 \%(64 \%)$ in HB-partial. These results reinforce our finding that information on prior decision-makers' dishonesty is indeed a robust and powerful force in affecting subsequent dishonest behavior, especially when it is suggestive of high dishonesty, and information on benefit from dishonesty for those prior decision-makers does not affect behavior of later decision-makers in any significant way. These findings also help justify the directional nature of parts (b) and (c) of the hypotheses.

Table 8

Results on Lying in Additional Treatments.

\begin{tabular}{|c|c|c|c|c|c|c|c|}
\hline Treatments & $\begin{array}{l}\text { Number } \\
\text { of } \\
\text { Senders }\end{array}$ & $\begin{array}{l}\text { Number of } \\
\text { lying } \\
\text { Senders }\end{array}$ & $\begin{array}{l}\text { Proportion of } \\
\text { Lying Senders }\end{array}$ & $\begin{array}{l}\text { vs. LB- } \\
\text { high_norm } \\
74 \%(71 \%)\end{array}$ & $\begin{array}{l}\text { vs. HB- } \\
\text { low_norm } \\
71 \%(61 \%)\end{array}$ & $\begin{array}{l}\text { vs. LB } \\
\text { Control } \\
57 \% \\
(53 \%)\end{array}$ & $\begin{array}{l}\text { Belief } \\
\text { about } \\
\text { Lying } \\
\text { Proportion }\end{array}$ \\
\hline LB-partial & $\begin{array}{l}46 \\
(46)\end{array}$ & $\begin{array}{l}36 \\
(35)\end{array}$ & $\begin{array}{l}78 \% \\
(76 \%)\end{array}$ & $\begin{array}{l}Z=0.44 \\
p=0.660 \\
(Z=0.60 \\
p=0.595)\end{array}$ & - & - & $\begin{array}{l}73 \% \\
(60 \%)\end{array}$ \\
\hline HB-partial & $\begin{array}{l}44 \\
(44)\end{array}$ & $\begin{array}{l}30 \\
(28)\end{array}$ & $\begin{array}{l}68 \% \\
(64 \%)\end{array}$ & - & $\begin{array}{l}Z=-0.30, \\
p=0.763 \\
(Z=0.29, \\
p=0.769)\end{array}$ & - & $\begin{array}{l}68 \% \\
(49 \%)\end{array}$ \\
\hline LB-example & $\begin{array}{l}42 \\
(36)\end{array}$ & $\begin{array}{l}23 \\
(20)\end{array}$ & $\begin{array}{l}55 \% \\
(56 \%)\end{array}$ & - & - & $\begin{array}{l}Z=-0.19, \\
p=0.850 \\
(Z=0.26, \\
p=0.798)\end{array}$ & $\begin{array}{l}69 \% \\
(49 \%)\end{array}$ \\
\hline
\end{tabular}

Note: The results from the India experiment are reported within parentheses. Z-statistics are calculated for the difference in proportions in row and column treatments in the above matrix. All tests reported are two-tailed (alternative hypothesis, $\mathrm{H}_{1}$ : row $\neq$ column).

The second issue we address in this section deals with potential experimenter demand effect created by the information transmission process in the intervention treatments (LB-high_norm and HB-low_norm). Specifically, we are interested to check if the provided information on lying from prior sessions created an "example" the senders might have thought they were expected to follow. To accomplish this goal, we ran an 
additional treatment labeled as LB-example. This treatment is identical to LB-partial in every respect with only one exception: though information on past senders' lying was given in the instructions to the senders in LBexample, they were not told explicitly that this information came from actual past sessions; instead, they were told that the purpose of the information was just to give them an example on how the outcomes of a session may look like. If an example could create experimenter demand effects in our intervention treatments, then that should also be true for LB-example as well, and by extension, the proportion of lie would be higher in LB-example than in LB Control. ${ }^{22}$

As Table 8 shows, only 55\% (56\%) of the senders in LB-example chose to lie and this proportion is statistically identical to that in LB Control. As such, we observe that a mere example does not affect senders' preferences for lying - it only matters when the example is suggestive of a norm of actual behavior (as in LB-high_norm and HB-low_norm). ${ }^{23}$ Therefore, we gather that the treatment effects we observed did not originate from any experimenter demand effect, but they were results of the 'norm' conveyed by the transmitted information in the intervention treatments.

The third issue we focus on in this section is another confounding factor which may have impacted our results. One may contend that the difference observed in propensity to lie between LB Control (HB Control) and LBhigh_norm (HB-low_norm) is due to changes in senders' selfishness. We do not test for this conjecture; instead, we rely on the findings in Innes and Mitra (2013). They tested this conjecture and found that intervention on dishonesty norm changed preferences for lying in a deception game, but not selfishness in a control dictator game (see Table 3 in Innes \& Mitra, 2013). We, therefore, rule out changes in selfishness as a possible explanation of our treatment differences.

We bring this section to an end by recognizing a limitation of the type of substitutability (between benefit from lying and perceived norm of lying) we proposed and observed in the data. Our argument holds when the change in benefit is moderate. Of course, senders' lying behavior is likely to show substantial responsiveness when the benefit from lying changes a lot (e.g. a lowering of the payoff from lying that makes lying almost equivalent to telling the truth in terms of the payoff). In that case, intervention of perceived norm is unlikely to counteract the effects of the change in benefit. We also acknowledge that our experiment does not establish the rate of substitution between benefit from lying and perceived norm of lying; our results only establish the possibility of the substitution.

\section{Summary}

We started off with a clear objective of focusing on the impact of pecuniary and non-pecuniary motives on human behavior. Specifically, our interest was to test if changes in the perception of a descriptive norm of lying could counteract the opposing impact of changes in the pecuniary benefit from lying. We designed experimental treatments where these two motives were carefully calibrated to operate in opposite directions and found partial evidence that the non-pecuniary motive could counteract its pecuniary counterpart. Subsequent treatments further established this result by removing possible confounding factors.

Our findings provide an indirect explanation for a critical empirical trend emerging across the globe. Majority of the people worldwide believe corruption in their country is getting worse (page 3, Global Corruption Barometer, 2013, Transparency International). ${ }^{24}$ A plethora of factors determine why countries remain entangled in corruption/dishonesty. We trace out a fundamental behavioral reason for the intransigency of dishonesty: individuals are guided by the prevailing social norm, only if it is in consonance with their "homo economicus" attitude. Given that societal norms do not change overnight, future work may focus on developing mechanisms 
with a view to eradicating dishonesty gradually. It is important to underscore that any attempt to improving the stringency of anticorruption laws should be carefully calibrated with the fact that the process of change in norms related to dishonesty is rather sluggish.

\section{Uncited reference}

International Country Risk Guide Data, xxxx.

\section{References}

The corrections made in this section will be reviewed and approved by a journal production editor. The newly added/removed references and its citations will be reordered and rearranged by the production team.

Abbink, K., Freidin, E., Gangadharan, L., \& Moro, R. (2018). The Effect of Social Norms on Bribe Offers. Journal of Law, Economics, and Organization, 34, 457-474.

Allcott, H. (2011). Social Norms and Energy Conservation. Journal of Public Economics, 95, 1082-1095. Alpízar, F., and P. Martinsson, 2010. “Don’t Tell Me What to Do, Tell Me Who to Follow!” Environment for Development Working Paper DP 10-16. Gothenburg, Sweden.

Banerjee, R. (2016). Corruption, norm violation and decay in social capital. Journal of Public Economics, $137,14-27$.

Banerjee, R. (2015). On the interpretation of bribery in a laboratory Corruption game: Moral frames and social norms. Experimental Economics, 19, 240-267.

Banerjee, R., \& Mitra, A. (2018). On monetary and non-monetary interventions to combat corruption. Journal of Economic Behavior and Organization, 149, 332-355.

Bardhan, P. (1997). Corruption and Development: A Review of Issues. Journal of Economic Literature, $35,1320-1346$.

Bardsley, N., \& Sausgruber, R. (2005). Conformity and Reciprocity in Public Good Provision. Journal of Economic Psychology., 26, 664-681.

Bartels, D.M., Bauman, C.W., Cushman, F.A., Pizarro, D.A., \& McGraw, A.P. (2015). Moral Judgment and Decision making. John Wiley \& Sons Ltd, 478-515.

Battigalli, P., Charness, G., \& Dufwenberg, M. (2013). Deception: The Role of Guilt. Journal of Economic Behavior \& Organization, 93, 227-232.

Becker, G.S. (1996). Accounting for Tastes. Harvard University Press.

Bernheim, B.D. (1994). A Theory of Conformity. Journal of Political Economy, 102, 841-877.

Biccheiri, C. (2006). The Grammar of Society: The Nature and Dynamics of Social Norms. New York: Cambridge University Press. 
Bicchieri, C., \& Xiao, E. (2009). Do the Right Thing: But Only if Others Do So. Journal of Behavioral Decision Making, 22, 191-208.

Bobek, D.D., Hageman, A.M., \& Kelliher, C.F. (2013). Analyzing the Role of Social Norms in Tax Compliance Behavior. Journal of Business Ethics, 115, 451-468.

Bobek, D.D., Roberts, R.W., \& Sweeney, J.T. (2007). The Social Norms of Tax Compliance: Evidence from Australia, Singapore, and the United States. Journal of Business Ethics, 74, 49-64.

Bohnet, I., \& Zeckhauser, R. (2004). Social Comparisons in Ultimatum Bargaining. Scandinavian Journal of Economics, 106, 495-510.

Bucciol, A., Landini, F., \& Piovesan, M. (2013). Unethical Behavior in the Field: Demographic Characteristics and Beliefs of the Cheater. Journal of Economic Behavior \& Organization, 93, 248-257.

Carlsson, F., García, J.H., \& Löfgren, Å. (2010). Conformity and the Demand for Environmental Goods. Environmental and Resource Economics, 47, 407-421.

Charness, G., \& Dufwenberg, M. (2010). Bare promises: An experiment. Economics Letters, 107(2), 281-283.

Carpenter, J.P. (2004). When in Rome: Conformity and the Provision of Public Goods. Journal of SocioEconomics, 33, 395-408.

Cason, T., \& Mui, V. (1998). Social Influence in the Sequential Dictator Game. Journal of Mathematical Psychology, 42, 248-265.

Cialdini, R., and Trost, M. R. (1998). Social influence: Social norms, conformity, and compliance. D. T. Gilbert, S. T. Fiske, \& G. Lindzey (Eds.), The handbook of social psychology. Boston: Oxford University Press.

Diekmann, A., Przepiorka, W., \& Rauhut, H. (2015). Lifting the veil of ignorance: An experiment on the contagiousness of norm violations. Rationality and Society, 27, 309-333.

Dimant, E. (2019). Contagion of Pro- and Anti-Social Behavior Among Peers and the Role of Social Proximity. Journal of Economic Psychology, 73, 66-88.

Dreber, A., \& Johannesson, M. (2008). Gender differences in deception. Economics Letters, 99, 197199.

Duffy, J., \& Kornienko, T. (2010). Does Competition Affect Giving?. Journal of Economic Behavior and Organization, 74, 82-103.

Dugar, S., Mitra, A., \& Shahriar, Q. (2019). Deception: The Role of Uncertain Consequences. European Economic Review, 114, 1-18.

Egebark, J., Ekström, M. (2011). Like What You Like or Like What Others Like? Conformity and Peer Effects on Facebook. IFN Working Paper No. 886. Stockholm Sweden.

Ellingsen, T., Johannesson, M., Lilja, J., \& Zetterqvist, H. (2009). Trust and truth. The Economic Journal, 119(534), 252-276. 
Ferraro, P.J., \& Price, M.K. (2013). Using Nonpecuniary Strategies to Influence Behavior: Evidence from a Large-scale Field Experiment. Review of Economics and Statistics, 95, 64-73.

Ferraro, P.J., Miranda, J.J., \& Price, M.K. (2011). The Persistence of Treatment Effects with Norm- Based Policy Instruments: Evidence from a Randomized Environmental Policy Experiment. American Economic Review, 101, 318-322.

Fehr, E., \& Gächter, S. (2000). Fairness and retaliation: The economics of reciprocity. The Journal of Economic Perspectives, 14(3), 159-181.

Festinger, L. (1954). A Theory of Social Comparison Processes. Human Relations, 7, 117-140.

Fischbacher, U., \& Föllmi-Heusi, F. (2013). Lies in Disguise - An Experimental Study on Cheating. Journal of the European Economic Association, 11, 525-547.

Fischer, P., \& Huddart, S. (2008). Optimal Contracting with Endogenous Social Norms. American Economic Review, 98, 1459-1475.

Fortin, B., Lacroix, G., \& Villeval, M. (2007). Tax evasion and social interactions. Journal of Public Economics, 93, 279-284.

Fosgaard, T.R., Hansen, L.G., \& Piovesan, M. (2013). Separating Will from Grace: An experiment on conformity and awareness in cheating. Journal of Economic Behavior and Organization, 93, 384-391.

Freeman, R.B., \& Gelber, A.M. (2010). Prize structure and information in tournaments: Experimental evidence. American Economic Journal: Applied Economics, 2(1), 149-164.

Frey, B.S., \& Meier, S. (2004). Social Comparisons and Pro-social Behavior: Testing Conditional Cooperation in a Field Experiment. American Economic Review, 94, 1717-1722.

Galeotti, F., Kline, R., \& Orsini, R. (2017). When foul play seems fair: Exploring the link between just deserts and honesty. Journal of Economic Behavior \& Organization, 142, 451-467.

Gibson, R., Tanner, C., \& Wagner, A.F. (2013). Preferences for Truthfulness: Heterogeneity among and within Individuals. American Economic Review, 103, 532-548.

Gino, F., Ayal, S., \& Ariely, D. (2009). Contagion and Differentiation in Unethical Behavior. Psychological Science, 20, 393-398.

Gneezy, U. (2005). Deception: The Role of Consequences. American Economic Review, 95, 384-394.

Global Corruption Barometer, 2013. The Transparency International, Berlin.

Goeree, J.K., \& Yariv, L. (2015). Conformity in the Lab. Journal of the Economic Science Association, 1, $15-28$.

Goldstein, N.J., Cialdini, R.B., \& Griskevicius, V. (2008). A Room with a Viewpoint: Using Social Norms to Motivate Environmental Conservation in Hotels. Journal of Consumer Research, 35, 472-482.

Graham, J., Meindl, P., Beall, E., Johnson, K.M., \& Zhang, L. (2016). Cultural Differences in Moral Judgment and Behavior, Across and Within Societies. Current Opinion in Psychology, 8, 125-130. 
Houser, D., Vetter, S., \& Winter, J. (2012). Fairness and cheating. European Economic Review, 56, $1645-1655$.

Hugh-Jones, D. (2016). Honesty, Beliefs about Honesty, and Economic Growth in 15 Countries. Journal of Economic Behavior and Organization, 127, 99-114.

Hurkens, S., \& Kartik, N. (2009). Would I lie to you? On social preferences and lying aversion. Experimental Economics, 12, 180-192.

Innes, R., \& Mitra, A. (2013). Is Dishonesty Contagious?. Economic Inquiry, 51, 722-734.

International Country Risk Guide Data. The PRS Group, New York.

Kajackaite, A., \& Gneezy, U. (2017). Incentives and cheating. Games and Economic Behavior, 102, $433-444$.

Keizer, K., Lindenberg, S., \& Steg, L. (2008). The Spreading of Disorder. Science, 12, 1681-1685.

Krupka, E., \& Weber, R. (2008). The Focusing and Observational Effects of Social Norms. Carnegie Mellon University. Working paper.

Krupka, E., \& Weber, R. (2009). The Focusing and Informational Effects of Norms on Pro-Social Behavior. Journal of Economic Psychology, 30, 307-320.

Lefebvre, M., Pestieau, P., Riedl, A., \& Villeval, M. (2015). Tax evasion and social information: An experiment in Belgium, France, and the Netherlands. International Tax and Public Finance, 22, 401-425.

Lundquist, T., Ellingsen, T., Gribbe, E., \& Johannesson, M. (2009). The aversion to lying. Journal of Economic Behavior \& Organization, 70(1), 81-92.

Pruckner, G.J., \& Sausgruber, R. (2013). Honesty on the Streets: A Field Study on Newspaper Purchasing. Journal of the European Economic Association, 11, 661-679.

Rauhut, H. (2013). Beliefs about Lying and Spreading of Dishonesty: Undetected Lies and Their Constructive and Destructive Social Dynamics in Dice Experiments. PLoS ONE, 8, 1-8.

Rege, M. (2004). Social Norms and Private Provision of Public Goods. Journal of Public Economic Theory, 6, 65-77.

Reuben, E., \& Riedl, A. (2013). Enforcement of contribution norms in public good games with heterogeneous populations. Games and Economic Behavior, 77, 122-137.

Reuben, E., \& Stephenson, M. (2013). Nobody likes a rat: On the willingness to report lies and the consequences thereof. Journal of Economic Behavior and Organization, 93, 384-391.

Rosenbaum, S., Billinger, S., \& Stieglitz, N. (2014). Let's be Honest: A Review of Experimental Evidence of Honesty and Truth-telling. Journal of Economic Psychology, 45, 181-196.

Salmon, T.C., \& Serra, D. (2017). Corruption, social judgment and culture: An experiment. Journal of Economic Behavior and Organization, 142, 64-78. 
Shang, J., \& Croson, R. (2009). A Field Experiment in Charitable Contribution: The Impact of Social Information on the Voluntary Provision of Public Goods. Economic Journal, 119, 1422-1439.

Smith, K.D., Smith, S.T., \& Christopher, J.C. (2007). What Defines the Good Person? Cross-cultural Comparisons of Experts' Models with Lay Prototypes. Journal of Cross-Cultural Psychology, 38, 333360.

Soraperra, I., Weisel, O., Zultan, R., Kochavi, S., Leib, M., Shalev, H., \& Shalvi, S. (2017). The bad consequences of teamwork. Economics Letters, 160, 12-15.

Sutter, M. (2009). Deception through Telling the Truth? Experimental Evidence from Individuals and Teams. Economic Journal, 119, 47-60.

Traxler, C. (2010). Social norms and conditional cooperative taxpayers. European Journal of Political Economy, 26, 89-103.

Velez, M.A., Stranlund, J.K., \& Murphy, J.J. (2009). What Motivates Common Pool Resource Users? Experimental Evidence from the Field. Journal of Economic Behavior Organization, 70, 485-497.

Wenzel, M. (2005). Misperceptions of social norms about tax compliance: From theory to intervention. Journal of Economic Psychology, 26, 862-883.

Wenzel, M. (2005). Motivation or rationalization? Causal relations between ethics, norms and tax compliance. Journal of Economic Psychology, 26, 491-508.

Wenzel, M. (2004). An analysis of norm processes in tax compliance. Journal of Economic Psychology, 25, 213-228.

Zafar, B. (2011). An Experimental Investigation of Why Individuals Conform. European Economic Review, 55, 774-798.

\section{Footnotes}

\section{Text Footnotes}

[2] A large literature on conformity to norms which establishes that norm can induce behavior ( Allcott, 2011; Alpízar and Martinsson, 2010; Bardsley \& Sausgruber, 2005; Becker, 1996; Bernheim, 1994; Biccheiri, 2006; Bicchieri \& Xiao, 2009; Bohnet \& Zeckhauser, 2004; Carlsson, García, \& Löfgren, 2010; Carpenter, 2004; Cason \& Mui, 1998; Egebark and Ekström, 2011; Ferraro, Miranda, \& Price, 2011; Ferraro \& Price, 2013; Festinger, 1954; Fischer \& Huddart, 2008; Frey \& Meier, 2004; Goeree \& Yariv, 2015; Goldstein, Cialdini, \& Griskevicius, 2008; Innes \& Mitra, 2013; Keizer, Lindenberg, \& Steg, 2008; Krupka \& Weber, 2008; Shang \& Croson, 2009; Velez, Stranlund, \& Murphy, 2009; Zafar, 2011).

[3] In specific terms, our research is based on the concept of descriptive norm, which represents the standards that originate from others' actual behavior. See Cialdini and Trost (1998) for a discussion on the classification of social norms.

[4] We notice a stylized fact in a proprietary dataset maintained by the International Country Risk Guide (ICRG), which publishes country-level data on political, economic, financial, and 
composite risk ratings. (i) In a sample of 124 countries for which data is consistently available, the average law and order (LO) score has improved from 3.02 (out of a maximum of 6) in 1990 to 3.64 in 2010. (ii) For these 124 countries, the average corruption score (inverse measure: higher is better) has declined from 3.33 (out of a maximum of 6) in 1990 to 2.73 in 2010. (iii) For the set of 75 countries that (had weak LO situation and) were placed in the lower half $(<=$ 3 ) of the possible score range in 1990, the average LO score has markedly improved from 1.91 in 1990 to 3.11 in 2010. (iv) For these 75 countries with marked LO improvement between 1990 and 2010, the corresponding average corruption score has worsened from 2.66 to 2.19. (v) Narrowing down further, for the 40 most corrupt countries, the average corruption score has gone down even though the average LO score has improved over the same time-range. Admittedly, these numbers are coarse, and they raise many complex questions on cause and effect. However, since the size of the sample is large, the general trend discussed above cannot be ignored. (The summary statistics and the description of the indexes are available from the authors.)

[5] Strictly speaking, we are not suggesting that dishonesty and corruption are the same phenomenon. However, by and large, the literature on corruption/dishonesty interchangeably uses these two terms. See Bardhan (1997) for an excellent discussion on this topic.

[6] We are thankful to an associate editor and two reviewers for drawing our attention to some of these works.

[7] Rosenbaum, Billinger, and Stieglitz (2014) provide a detailed survey of the literature on lying/dishonesty.

[8] For expositional purposes, we shall consider the sender (receiver) as female (male) throughout the paper.

[9] To remain neutral with labeling, we varied the option labels (A or B) across senders in the experiment. For some senders, Message-A was truthful, and for the others, Message-B. For expositional simplicity, however, we will assume throughout the paper that Message-A is the lie.

[10] Gneezy (2005) shows that senders' propensity to lie in the deception game increases with benefit from lying $(=x-m)$ and decreases with the potential cost imposed on the receiver $(=n$ $-y$ ). Using a dictator control treatment, he also shows that decision-making in the deception game is not the same as in the dictator game, as there is a psychological cost to lying in the deception game.

[11] We tried to remain consistent between the US payoffs and the Indian payoffs. While deciding on the Indian payoffs, we used three different criteria, which were: (i) the purchasing power parity (PPP) factor between US Dollar and Indian Rupee $(\$ 1 \approx \mathrm{Rs} 17)$ (http://data.worldbank.or g/indicator/PA.NUS.PPP), (ii) a minimum expected payoff of Rs 200 for each participant, and (iii) conversion of the resulting number from (i) and (ii) into the nearest focal number. For instance, $\$ 5$ (\$19) would be equivalent to Rs 85 (Rs 323) in PPP terms. To ensure a minimum expected payoff of Rs 200, an amount of Rs 115 was added to make the payoffs Rs 200 (Rs 438). Finally, we converted Rs 438 into the nearest focal number of Rs 450. The same procedure was adopted to determine the payoff of Rs 325 under LB. 
[12] One can also think about two more treatments in which the LB (HB) game is played and the subjects are provided information on payoffs and lying behavior from an earlier LB (HB) treatment. In other words, in these two treatments participants playing the LB game would be exposed to prior-session information involving a low level of lying (from past LB Control sessions), and likewise for the HB game. We did not conduct these treatments because, as we would see in the Results section, that the actual level of lying in the LB (HB) treatment was not much different from the (un-intervened) belief about the propensity to lie in this treatment. As a result, there would not be much room for any intervention regarding belief. Also, for instance, if the intensity of lying in LB-high_norm was significantly higher than the same in LB, then a putative "HB-high_norm" treatment would likely result in an even greater lying intensity than the same in the HB treatment. It is important to understand that such a research question is not particularly interesting, because it is tantamount to asking how people would behave in a culture of high dishonesty in which the benefit from dishonesty is also high. As such, we have not designed treatments like "HB-high_norm" and "LB-low_norm".

[13] Recall that the senders in the intervention treatments are provided with two pieces of information from prior sessions - (i) payoff from lying and (ii) level and proportion of lying. When determining the directionality in parts (b) and (c) of our hypotheses based on the extant literature, we make an implicit assumption that the information on others' payoffs does not produce any confounding effect. In other words, the expected effect on lying in the intervention treatments is produced by part (ii) of the information. As we mentioned in Section I, we conduct partial information treatments which provide a direct test of this assumption and find support for it. These treatments are discussed in detail in the Discussion section.

[14] According to Hugh-Jones (2016), the US and India differ in terms of honesty. He finds that beliefs about honesty are not correlated with reality in either country.

[15] Indeed, approximately $82 \%$ of the receivers in our experiment followed the matched sender's recommendation.

[16] Since our experiment implemented a between-subjects design, a given subject was not exposed to more than one treatment condition. As a result, we do not need to follow any particular order to compare the data. For instance, if $p_{H B}>p_{L B}$, then $\left(p_{H B}-p_{L B}\right)$ measures the increase in lying propensity due to an increase in benefit, while $-\left(p_{L B}-p_{H B}\right)$ describes the decrease in lying propensity due to a decrease in benefit. However, we do not know or make any attempt to predict how these comparisons would look like in a within-subjects design, in which subjects participate in multiple treatments in different order. That is, we do not know whether $\left(p_{H B}^{1}-p_{L B}^{2}\right)$ and $-\left(p_{L B}^{1}-p_{H B}^{2}\right)$, where the superscript denotes the order in which subjects participate in the treatments, would be the same.

[17] In a one-tailed Mann-Whitney test for the difference in mean, we observe $p=0.034$ ( $p=$ $0.015)$.

[18] In a one-tailed Mann-Whitney test for the difference in mean between the beliefs in LBhigh_norm and LB Control, we observe $p=0.084(p=0.003)$. 
In a one-tailed Mann-Whitney test for the difference in mean between the beliefs in $\mathrm{HB}$ low_norm and HB Control, we observe $p=0.001(p=0.039)$.

[20] The rationale for using Tobit models is that belief is a continuous variable with upper and lower bounds.

[21] Using a one-tailed Wald test, we reject the null hypothesis that the coefficients of HB$l o w \_n o r m$ and HB are the same $(p=0.001(p=0.003)$ in the US (India) regression).

[22] One can also think about another treatment which is similar to HB-partial in every respect except that senders in this treatment would not be told explicitly that the information on lying they are provided with are from actual prior sessions. We decided not to conduct this treatment because we found that senders in HB-partial did not respond much to the information on lying in prior sessions, despite knowing it was real. It is then unlikely that the information will have any significant effect on sender behavior when they are not explicitly told that the information they are given are real.

[23] Another evidence against experimenter demand effect can be established from the test results for the main treatments in Table 4. If the significant difference between LB Control and LBhigh_norm is driven by demand effect, then the same demand effect could have led to a significant difference between HB Control and HB-low_norm but that was not the case.

[24] The publication is available at: http://www.transparency.org/gcb2013/report. 